\title{
A PERCEPÇÃO AMBIENTAL DOS MORADORES DO ENTORNO DO RIO ARIRI, ANANINDEUA/PA
}

Odilena de Jesus Moraes FREITAS ${ }^{11}$ PPCA/Universidade de Taubaté odilena@globo.com

Ana Aparecida da Silva ALMEIDA ${ }^{22}$ PPCA/Universidade de Taubaté anaparecida.almeida@gmail.com Ricardo Augusto Gomes PEREIRA ${ }^{33}$

ICED/UFPA rapereira@ufpa.br

Resumo: A comunidade próxima ao rio Ariri, no município de Ananindeua/PA, caracterizou-se pelo crescimento populacional, o que resultou em gradativo processo de deterioração do rio. Com este estudo, objetivou-se analisar a percepção ambiental dos moradores do entorno desse rio, a fim de apontar as inter-relações homem-ambiente, como as perspectivas, satisfações, descontentamentos, avaliações e comportamentos dos sujeitos pesquisados. Para alcançar este objetivo, a pesquisa se desenvolveu de forma exploratório-descritiva, com aplicação de questionário contendo perguntas semiabertas para 353 sujeitos. Os resultados mostram que o crescimento desordenado ocasionou a degradação ambiental do rio, sendo que o lixo produzido pela população local constitui-se na maior ameaça à sua preservação. Essa percepção aponta uma inter-relação entre as condições básicas de saúde e a problemática ambiental, o que contribuiu para uma baixa qualidade de vida da população pesquisada.

Palavras-chave: Comunidade. Degradação ambiental. Urbanização. Percepção ambiental.

Abstract: The community near the river in the district Ananindeua- Ariri /Pa. characterized by population growth which resulted in gradual process of deterioration

\footnotetext{
${ }^{1}$ É Licenciada Plena em Língua Portuguesa e Literatura pela Universidade Federal do Pará; Mestranda em Ciências Ambientais pela UNITAU/SP; PPG/CA/UNITAU.

${ }^{2}$ Possui graduação em Ciências Biológicas pela Universidade Estadual Paulista Júlio de Mesquita Filho; Doutorado em Agronomia (Solos e Nutrição de Plantas) pela Universidade de São Paulo (1997). PPG/CA/UNITAU.

${ }^{3}$ Possui graduação em licenciatura plena em pedagogia pela Universidade da Amazônia; Mestrado em Gestão e Desenvolvimento Regional Pela UNITAU/SP; Professor Substituto do Instituto de Ciências da Educação da Universidade Federal do Pará/ UFPA.
}

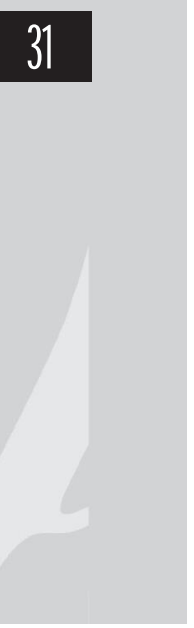


of the river population. This study aimed to analyze the environmental awareness of people living around the river Ariri in Ananindeua, State of Pará, in order to point out the inter-relations man-environmental, the prospects, satisfactions, dissatisfaction and conduct evaluations of the subjects studied. To achieve this goal, the research unfolded exploratory-descriptive with a questionnaire with semi-open questions to 353 individuals. The results show that the uncontrolled growth caused environmental degradation of the river, and the waste produced by the local population constitutes the greatest threat to it's preservation. This perception suggests an interrelationship between the basic conditions of health and environmental problems, which contributes to a lower quality of life the population surveyed.

Keywords: Community. Environmental degradation. Urbanization. Environmental perception.

\section{Introdução}

A efetivação de políticas públicas ambientais em áreas de ocupação territorial inclui-se como o centro de muitas propostas de universalização do atendimento às necessidades de comunidades residentes nessas áreas, ao mesmo tempo em que alcança a questão do enfrentamento dos desafios em busca de cidadania, sendo isso o principal objeto de investigação do presente estudo, bem como o das verificações realizadas no âmbito do Programa de Pós-Graduação em Ciências Ambientais da Universidade de Taubaté (UNITAU).

Assim, para situar esse objeto, a pesquisa se desenvolveu no município de Ananindeua, integrante da Região Metropolitana de Belém (RMB), situado ao nordeste do Estado, com uma população estimada em 505.512 habitantes, distribuídos em uma área de $185 \mathrm{~km}^{2}$, correspondentes a 39,72\% da Região Metropolitana (RM). O nome Ananindeua é de origem tupi e deve-se a grande quantidade de árvore chamada anani (Synfonia gobulifera), uma árvore que produz a resina de cerol utilizada para lacrar as fendas das embarcações. A caracterização preliminar de sua população aponta que esse município originalmente foi considerado "cidade dormitório", apresentando um considerável

\footnotetext{
${ }^{4}$ Ananindeua recebe o título de "cidade dormitório"em decorrência de seu caráter principalmente residencial, na qual a maioria de seus moradores trabalha em uma cidade próxima (Belém) por ter maior desenvolvimento econômico.
} 
desenvolvimento nos últimos anos, uma vez que vem crescendo de forma espontânea, embora sem planejamento e/ou diretrizes urbanísticas, criando situações de confronto entre o suporte natural e os objetos construídos.

Diante dessa distinção, a problemática que se verificou nos estudos realizados no PPG/CA da UNITAU estão relacionados à percepção do meio ambiente em que está inserida a população do entorno do rio Arari, sobre o qual se questionou a degradação ambiental tida como consequência da proliferação da ocupação desordenada dos espaços nas periferias das metrópoles, em razão da ausência de políticas públicas habitacionais efetivas.

De acordo com Mello (2002), tal problemática se justifica a partir do que o autor aponta, considerando que o desenvolvimento do município se estabelece paralelo a um processo crescente de degradação ambiental, em que são praticadas constantemente agressões contra a boa climatização, a correta drenagem, as áreas verdes, os cursos hídricos e a topografia original, citando-se como exemplo a Ocupação denominada 28 de Agosto, no município de Ananindeua, uma área de ocupação urbana, que se desenvolveu em decorrência do crescente déficit habitacional na Região Metropolitana de Belém, aliado à ausência de políticas públicas voltadas para o problema habitacional daquela área, criando um espaço dual: de um lado, a cidade formal, que concentra os investimentos públicos, e, de outro, seu contraponto absoluto, a cidade informal, que continua a crescer sem atributos de urbanidade, exacerbando as diferenças socioambientais.

Neste sentido, o objetivo desse estudo é apresentar os resultados da análise da percepção ambiental dos moradores do entorno do rio Ariri, em Ananindeua, estado do Pará, a fim de apontar as inter-relações homemambiente, assim como perspectivas, satisfações, descontentamentos, avaliações e comportamentos dos seus habitantes.

Para atingir tal objetivo, optou-se por um estudo de caráter exploratório descritivo, por se acreditar que essa forma permite ao pesquisador conhecer a problemática e as variáveis que concorrem para sua definição, além de admitir enxergar as perspectivas de respostas, pois objetivam, segundo, Marconi e Lakatos (2007, p. 190), "descrever completamente determinado fenômeno", qualitativo, uma vez que "o 
sujeito observador é a parte integrada do processo de conhecimento e interpreta significados" (1998, p. 79).

Como já exposto, o estudo se desenvolveu no município de Ananindeua no estado do Pará, onde se localiza o lócus da pesquisa de campo que denominamos de entorno do rio Arari, área, que é cortada por esse rio e está localizada entre a Rodovia 40 Horas e a Avenida Independência, ambas no município supra mencionado. Nessa área, habitam aproximadamente 4.300 famílias, que lá se instalaram exatamente no dia 28 de agosto de 1994, data esta que deu origem ao nome da área de ocupação. ${ }^{55}$

Atualmente, o rio encontra-se com algumas partes do percurso assoreado, com árvores tombadas para dentro de seu leito, favorecendo o acúmulo de lixo e inibindo a correnteza livre, pois se trata de um rio bastante sinuoso, o que lhe favorece a poluição.

Ainda é possível se ver uma área de bosque, um pouco acima da ocupação, que continua sendo utilizada para a exploração de frutos, principalmente a do açaí, fruto típico da região, muito apreciado pela população paraense em geral, bem como para depósito de variados tipos de lixo. Apesar de sua vegetação natural e original ter sido destruída, ainda existem árvores centenárias, algumas com os troncos queimados ou semiqueimados, como resultante da ação antrópica no local.

Essa comunidade organizou-se como associação: Associação dos Moradores do Jardim 28 de Agosto (AMJAG), e pleiteia junto à Prefeitura a execução do Projeto Sanear-Ananindeua, que foi aprovado com verbas do PAC e visa ao saneamento básico para três comunidades adjacentes, incluindo a área em estudo, trazendo água tratada, esgoto com uma central de tratamento, asfalto e a revitalização das áreas degredadas do rio que corta a ocupação. Desse quantitativo de ocupantes, 280 famílias serão remanejadas para o residencial Icuí-Guajará, que teve sua construção iniciada, mas, segundo informações do presidente daquela comunidade, estagnou por falta de verba.

Para a caracterização da área de estudo, foram utilizados documentos oficiais, programas, projetos, relatórios técnicos e documentos referentes à

\footnotetext{
${ }^{5}$ Informação verbal prestada pelo Presidente da Associação dos Moradores da Comunidade 28 de Agosto.
} 
área de ocupação denominada 28 de Agosto, no município de Ananindeua/ PA, como também vasta literatura sobre o tema para sustentação do problema levantado.

Dentre os conceitos estudados, a urbanização configurou-se em um dos mais importantes, pois, segundo Pires (2006, p. 84), deve-se analisar o "crescimento físico-estrutural da cidade" e as "transformações sociais e econômicas, impulsionadas por modernizações tecnológicas, nos setores industrial, comercial e de serviços", como forma de se estudar concretamente a gestão do território em área metropolitana e os impactos das ações governamentais, pois a "nova urbanização" é capaz de apresentar a "metrópole onipresente", e, com ela, "desorganizar e reorganizar, ao seu talante e em seu proveito, as atividades periféricas, impondo novas questões para o processo de desenvolvimento regional”.

Com isso, o que se verifica é que a urbanização é, de fato, concentradora da pobreza, pois grandes aglomerações urbanas da periferia, justamente em virtude da urbanização desigual, apresentam hoje, invariavelmente, um absoluto quadro de pobreza. Outra característica da urbanização desigual é o exagerado ritmo de crescimento das periferias pobres em relação aos centros urbanizados.

Diante do exposto, entende-se que o espaço é um elemento das forças produtivas da sociedade, ou seja, o seu conteúdo é o resultado da ação dos atores sociais. Nesse contexto, deve-se compreender que o espaço não é apenas econômico ou apenas um instrumento político que pretende homogeneizar as partes da sociedade, pelo contrário, considerando-se o espaço urbano, ele é o lócus de favelização, de ocupação desordenada das periferias das metrópoles e, portanto, das desigualdades sociais.

\section{A favelização de áreas urbanas: metrópoles e desigualdades sociais}

Segundo Fernandes (2001), a forma urbana é a organização dos elementos morfológicos (solo, edifícios, lotes, quarteirão, fachadas, praças, monumentos e mobiliário) que constituem e definem o espaço urbano. É a concepção final de toda transformação ocorrida na cidade durante o tempo por meio do homem. Está em conexão com o desenho, ou seja, com as linhas, com os espaços, os volumes, as geometrias, os 
planos e com as cores, constituindo a "arquitetura da cidade". É capaz de determinar a vida humana em comunidade, não estando vinculada apenas a concepções estéticas, ideológicas, culturais ou arquitetônicas, mas também a comportamentos, à utilização do espaço e à vida em comunidade, influenciando diretamente no bem-estar dos cidadãos, por meio das políticas públicas de urbanização que, no entanto, não abrangem todos os cidadãos.

Nesse sentido, levando-se em consideração as dificuldades habitacionais vividas pela população pobre, observa-se, segundo Hildebrandt (2004), a proliferação da ocupação de espaços nas periferias, uma vez que a população pobre e desempregada não possui condições de adquirir habitação digna para si e para sua família, sendo necessário se estabelecer em propriedades sem condições de moradia, podendo trazer grandes males à sua saúde e à sociedade.

Para Silva (2004), os pobres urbanos são um contingente da população que está vivendo abaixo das condições básicas de reprodução social e, portanto, fora do planejamento urbano e daquilo que se considera a "arquitetura da cidade". O autor observa ainda que estudos recentes assinalam que durante a década de 1990 ocorre um movimento cíclico de expansão e retratação do contingente de pobres nas áreas metropolitanas, com alta demanda para a habitação.

Assim, inicialmente é necessário caracterizar detalhadamente a habitação que, reconhecida como mercadoria, apresenta numerosas distinções particulares, podendo tanto ser encarada como bem de consumo, como bem de investimento.

Diversos autores têm indicado atributos especiais, que fazem da habitação um produto heterogêneo e diferenciado. Hildebrandt (2004, p. 39) destaca-a como um bem de consumo com natureza física típica, por ser grande, pesada e cara.

Abelém (1988) afirma que essas áreas de ocupação são subáreas invadidas por posseiros, formando unidades sociogeográficas facilmente observáveis e que possuem uma rede complexa de diversos tipos de relações, laços de parentesco e amizade ativos, uma organização social complexa e flexível. Expõe ainda que essas áreas de ocupação apresentam resistência e se confrontam com a organização das cidades e são pressionadas pelas instituições em termos de cobrança de taxas e 
impostos referentes aos serviços urbanos, pois usam ilicitamente os serviços e usufruem de seus benefícios, principalmente às proximidades das eleições, sendo que fora dessa época são entregues à própria sorte.

Ainda, segundo a autora, as áreas de ocupação surgem, também, em vista do aumento vegetativo da população e a intensificação do movimento migratório, associada à extrema pobreza e ao desemprego, originando três modalidades principais: a propagação de vilas; as passagens; e o assentamento da população de menor renda em moradias que se assentavam diretamente sobre a argila ou suspensas por estacas, em terrenos encharcados.

Dessa forma, a população pobre, não podendo morar nas áreas urbanas, em vista dos altos custos da terra, é "empurrada" para morar em áreas não propícias e, assim, essas áreas se transformam em enormes favelas (ABELÉM, 1988), sem atenção do poder público, sem o devido planejamento urbano, invadindo e explorando áreas que, em pouco tempo, sofrem sérias intervenções que degradam o meio ambiente, tomando-se como exemplo a Ocupação 28 de Agosto, em Ananindeua/ PA, localizada em uma área inicialmente esquecida pelo poder público, desvalorizada pelo mercado imobiliário, portanto ocupando um espaço não demandado por outros setores e que resultou na degradação do rio Ariri.

Nesse sentido, para Vieira e Weber (2002, p. 303), "a relação entre o homem e os recursos naturais renováveis que ele explora constituem o cerne dos problemas ambientais", principalmente em áreas ocupadas próximo a leitos de rios, que tendem, segundo os autores, a "sumir do mapa", sem que o poder público interfira, apesar da existência de ampla legislação ambiental de proteção aos rios e mananciais.

A teoria até aqui analisada mostra que é urgente a análise da forma como as populações são conduzidas a processos de favelização, considerando que tal condição gera esperanças e aprendizagens sociais de adaptação ao meio. Rotter (1966, p. 1 apud Ramos e Pereira 2011, p. 2) analisam essas adaptações como processos de assimilação que incorrem em "diferenças individuais e expectativas generalizadas".

A partir dessa perspectiva behaviorista, é possível definir um conceito, que em conformidade com Del Rio (1996), a percepção 
é entendida como um processo mental do indivíduo com o meio ambiente, a qual se dá por mecanismos perceptivos propriamente ditos e, principalmente, cognitivos. Nesse processo, quase todos os sentidos estão envolvidos, principalmente a visão, e o resultado de todos eles é a formação da imagem, mesmo de forma fragmentada, uma vez que "percepção é tanto a resposta dos sentidos aos estímulos externos, como a atividade proposital, na qual certos fenômenos são claramente registrados, [...]" (TUAN, 1980, p. 4).

Desse modo, a Percepção Ambiental é diferente para cada indivíduo, pois depende do lugar, personalidade e cultura, assim estabelecendo-se um valor individual às vivências dos indivíduos e, nesse sentido, para Tuan (1980, p. 05), a "Topofilia é o elo afetivo entre a pessoa e o lugar ou ambiente físico", sendo a percepção uma atividade e um "estender-se para o mundo" (p. 14) e, assim, as atitudes em relação à vida e ao meio ambiente refletem as variações individuais de percepção sobre o lugar ou a cidade onde vive.

Fernandes et al. (2008, p. 1) expõe que a Percepção Ambiental é definida como uma tomada de consciência do ambiente pelo homem; a percepção do ambiente no qual está inserido e, assim, "Cada indivíduo percebe, reage e responde diferentemente às ações sobre o ambiente em que vive. As respostas ou as manifestações daí decorrentes são resultado das percepções (individuais e coletivas) dos processos cognitivos, julgamentos e expectativas de cada pessoa".

Le Goff (1996) afirma que a percepção é insculpida na memória, que remete o homem a um conjunto de funções psíquicas que podem atualizar impressões ou informações passadas, e, nesse sentido, "o processo da memória no homem faz intervir não só a ordenação de vestígios, mas também a releitura desses vestígios". Dessa forma, Okamoto (2002) afirma que "não vemos a realidade absoluta, mas uma realidade percebida por meio de sentidos que reagem aos estímulos externos e internos, filtrada por condicionantes físicos, mentais e conceituais". Para Coelho (2002, p. 31), "Percepção ambiental pode ser definida como sendo uma tomada de consciência do ambiente pelo homem, ou seja, o ato de perceber o ambiente que se está inserido, aprendendo a proteger e a cuidar do mesmo". 
Observa-se, no entanto, que a forma individualizada de perceber o ambiente revela-se como uma dificuldade para a proteção dos ambientes naturais, haja vista os diferentes valores e importância atribuídos a essa questão por cada indivíduo ou grupo de indivíduos, que incutem na memória diferentes atributos e importância, segundo seus interesses e objetivos, pois, "Para compreender a preferência ambiental de uma pessoa necessitaríamos examinar sua herança biológica, criação, educação, trabalho e os arredores físicos. No nível de atitudes e preferências de grupo, é necessário conhecer a história cultural" (TUAN, 1980, p. 68).

Ou seja, para o autor, a percepção individual e/ou de grupos de indivíduos depende da cultura na qual estejam inseridos ou tenham sido criados ou educados, mediante o que são estabelecidas diferenças entre, por exemplo, a percepção ambiental de um nativo e a de um visitante, especialmente o turista, já que o nativo é imerso na totalidade de seu meio ambiente.

Nesse contexto, segundo o que expõe o autor, que se manifestam a apreciação estética, a familiaridade e a afeição, bem como o patriotismo em relação a um determinado lugar, permitindo a alteração de valores no sentido da valorização do meio ambiente.

\subsection{Resultados e discussão}

\subsubsection{A percepção ambiental do entorno do rio Ariri}

A pesquisa foi realizada com os 353 sujeitos pertencentes às famílias integrantes da Comunidade 28 de Agosto, no município de Ananindeua/ PA, nos meses entre Setembro e Dezembro de 2011, sendo todos maiores de 18 anos. Tal pesquisa revelou que 47\% declararam-se sem instrução; 9\% com nível fundamental; $40 \%$ com nível médio; 3\% com nível superior e $1 \%$ declararam-se como outros.

Buscou-se apurar a percepção dos entrevistados sobre como consideram a vida na Comunidade 28 de Agosto, tendo-se constatado que, para 3\% dos pesquisados, é Excelente; para 34\%, é Boa; para $44 \%$, é Regular; para 16\%, Péssima; $2 \%$ não quiseram responder e $1 \%$, outra opção. 
Os dados apresentados foram importantes para constatar que a maioria, isto é, 44\% das famílias da comunidade 28 de Agosto, apesar das dificuldades e dos problemas ambientais encontrados, consideram o modo de vida na comunidade como Regular. Não obstante, têm como referência a vida comparada aos bairros nobres da cidade em que há melhor qualidade de vida, visto que fatores, como saneamento básico, segurança, emprego etc., são precárias nesse local.

Observou-se que, ao longo dos anos, as famílias da comunidade, sem condições de adquirir moradias numa área mais adequada, construíram suas casas cada vez mais próximas do rio. A maioria em madeira, muitas em estilo palafitas, com sanitários cujos dejetos são despejados diretamente no rio Ariri. Estas casas, construídas sem qualquer planejamento, não possuem praticamente nenhuma infraestrutura, como sistemas hidráulico e sanitário.

Quando perguntados o que significava o meio ambiente, representado pelo rio Ariri, constatou-se que para $6 \%$ dos entrevistados, representa Qualidade de Vida; para 51\% representa Poluição; o conceito de Tranquilidade foi mencionado por apensas 1\% dos participantes; para 7\%, significa Terra, Água e Ar; para 22\%, Degradação Ambiental. 4\% consideram como Lugar de Saúde; 5\% como um Espaço Limpo, e para 4\% significa Conservação da Natureza.

$\mathrm{Na}$ visão da maioria dos entrevistados, o meio ambiente representado pelo rio Ariri é percebido como sinônimo de Poluição e Degradação Ambiental. Portanto, os participantes entendem que seus comportamentos com relação ao rio têm contribuído de forma significativa para a poluição dele.

Quando discorríamos sobre a utilidade, beleza e qualidade da água do rio, em tempos áureos; muitos se lembraram de como era agradável usufruir dos benefícios de um rio com águas limpas e cristalinas, onde era possível se ver a areia no fundo e a existência de vidas aquáticas, como peixes variados e muitos camarões; um rio útil, tanto para a comunidade como para os animais e vegetais. Por outro lado, entende-se que há uma carência de educação socioambiental, pois a maioria dos moradores desconhece noções básicas sobre conservação do meio ambiente.

Sobre a educação ambiental, o Art. 215, da Lei Orgânica do Município de Ananindeua, determina que o Poder Público Municipal 
deve criar Conselhos de Saúde, Saneamento e Meio Ambiente, que têm como função o acompanhamento, a avaliação e a fiscalização das ações pertinentes, para que se promova a educação ambiental multidisciplinar em todos os níveis das escolas municipais e designe informações necessárias ao desenvolvimento da consciência crítica da população para a preservação do meio ambiente naquele município. Além disso, deve prevenir e controlar a poluição, a erosão, o assoreamento e as outras formas de degradação ambiental. Entretanto, embora haja essa carência de conhecimento ambiental, todos têm consciência dos seus atos para com o meio ambiente; portanto, só precisam de estímulos para mudar suas atitudes com relação à natureza.

Esta constatação se confirma no momento em que os sujeitos foram indagados se conversam com os vizinhos sobre a conservação do meio. $34 \%$ dos informantes disseram que não, e, somente $63 \%$ relataram que costumam dialogar sobre o termo meio ambiente; e 3\% não quiseram responder.

É relevante mencionar que os problemas ambientais surgem devido à separação entre os seres humanos e a natureza. Assim sendo, o homem precisa tomar consciência de que é parte da natureza, e de que ela é uma descoberta verdadeiramente revolucionária numa sociedade que disso se esqueceu ao se colocar como projeto de dominação dela (GONÇALVES, 1998).

Portanto, é importante que os conviventes da Comunidade 28 de Agosto interajam entre si e dialoguem sobre as questões ambientais.

Dentre os $63 \%$ que responderam sim, indagou-se sobre quais assuntos são mais abordados. Constatou-se que a maioria, isto é, 59\% falam sobre lixo; $12 \%$ água; $8 \%$ desmatamento; $8 \%$ lançamento de dejetos no rio; $8 \%$ construção irregular de moradias e $5 \%$ sobre queimadas.

Observou-se que, entre a maioria dos participantes da pesquisa, a temática sobre lixo é predominante, considerando-se ser a parte visível da degradação ambiental causada pelo homem em sua intervenção na natureza e no meio ambiente.

Destaca-se que com a ocupação desordenada da área, o lixo foi se apresentando como um grave problema, o qual aumentou nos arredores das casas próximas ao rio, expandindo a poluição nesta área. 
Assim, entende-se que a preocupação com o acúmulo de lixo é evidente, e um dos fatores a contribuir para este acelerado quadro de degradação é o crescimento populacional desordenado, com precário ou quase nenhum saneamento básico. Assim, entende-se que as graves consequências são inevitáveis, tanto para os ecossistemas naturais, quanto para populações, o que compromete a qualidade de vida das pessoas (SILVA; SILVA, 1993).

Sobre essa questão, ressalta-se que não basta sensibilizar a comunidade para as questões de preservação do meio ambiente, sobretudo, é preciso que estas pessoas tenham uma vida digna, visto que as atitudes do homem e sua relação com a natureza refletem o estado de exploração e reproduzem o que aprendeu ao longo da sua história e da cultura da sociedade a que pertence (BERNA, 2003).

Os pesquisados foram indagados sobre as mudanças ambientais mais recentes no rio Ariri, constatando-se que, para $43 \%$ é o excesso de lixo; para $25 \%$ são as construções em locais proibidos; para $24 \%$ é o desmatamento; enquanto que $6 \%$ opinaram pelas queimadas; e, $2 \%$ não quiseram responder.

Considerando que a maioria dos entrevistados apontou o excesso de lixo como uma das grandes problemáticas e uma das mudanças ambientais mais recentes no rio Ariri, cabe aqui citar Ribeiro (2000, p. 55) quando menciona que: "o lixo resulta do consumo de bens e serviços em grande quantidade, que caracteriza as sociedades contemporâneas ditas desenvolvidas e os segmentos consumidores da população dos países em desenvolvimento".

Devido ao acúmulo de lixo nesta região, é possível observar na comunidade casos de doenças, como urticária (coceira), gripe, diarreia, verminoses, renite etc..

Perguntou-se ainda aos entrevistados quem são os responsáveis pelo surgimento dessas mudanças no rio Ariri. 39\% dos pesquisados, apontam o governo, pela insuficiência de limpeza pública e inexistência de saneamento básico. Todavia, $31 \%$ dos sujeitos consideram como responsável a própria comunidade. $27 \%$ atribuem a responsabilidade a cada um de nós. Para 2\%, são as organizações ecológicas e, para 1\%, são os cientistas. 
Isso confirma o que diz Gutiérrez (2000), que o cidadão crítico, além de reclamar, compreender, estabelecer seus direitos ambientais ao setor responsável e interessar-se por eles, também se dispõe ao exercício da sua responsabilidade ambiental. Para isso, controlam primeiramente sua vida cotidiana, econômica, social e ambiental, buscando associações para se fortalecer no mundo do mercado globalizado.

Quando inquiridos sobre suas contribuições acerca da solução para os problemas ambientais do rio Ariri, 66\% dos entrevistados afirmaram que tem contribuído, e 34\%, que não. Observou-se que a maioria dos moradores da comunidade diz fazer sua parte e contribuir para a solução dos problemas ambientais visíveis naquela localidade

Contudo, é notória a escassez de informações direcionadas à comunidade. Isso é falta de uma política educacional que possibilite uma mudança de comportamento, por meio da motivação e da sensibilização para que os sujeitos, habitantes da comunidade, que, sobretudo, são cidadãos, possam questionar de forma concreta a falta de iniciativa dos governos no sentido de efetivar políticas socioambientais.

Do mesmo modo, os informantes foram interrogados a indicar como a Comunidade 28 de Agosto poderia contribuir para a solução dos problemas ambientais existentes, atualmente, no rio Ariri, apurando-se que $24 \%$ opinou que a comunidade poderia contribuir conservando a natureza; $37 \%$, não deixando lixo no rio Ariri. $25 \%$ dos entrevistados afirmaram que a comunidade poderia contribuir cobrando das autoridades; 10\%, denunciando; e, 3\% afirmou não haver como contribuir.

Aquase totalidade dos sujeitos entrevistados reafirmou a necessidade de uma maior contribuição da comunidade no sentido de não depositar qualquer tipo de lixo às margens e/ou no leito do rio Ariri. Assim sendo, fica evidente a preocupação dos entrevistados com o crescente nível de degradação do rio.

Além disso, para reverter este quadro ou pelo menos diminuí-lo, a comunidade entende que é necessário, também, cobrar das autoridades, para que as diversas instâncias governamentais possam efetivar ações responsáveis e articuladas em busca do desenvolvimento da consciência ecológica local, da preservação e recuperação do rio que (ainda) existe na Comunidade, buscando restaurar o equilíbrio hídrico e ecológico local. 


\section{Conclusão}

A pesquisa teve como finalidade analisar a percepção ambiental dos moradores do entorno do rio Ariri, no município de Ananindeua/PA, e observou-se que, para a maioria dos informantes, a vida na comunidade é considerada regular, apesar das dificuldades e das problemáticas ambientais constatadas. Não obstante, esses moradores têm como referência a vida comparada aos bairros nobres da cidade em que há melhor qualidade de vida, visto que fatores, como saneamento básico, segurança, emprego, saúde etc., são precários e insuficientes nesta comunidade.

Como principais atributos sobre qualidade de vida, (vida saudável, emprego e morar em um lugar tranquilo), evidenciou-se que esses moradores têm uma considerável percepção ambiental, já que estes fatores podem ser associados ao meio ambiente, tendo em vista que este meio exterior ao organismo afeta o seu integral desenvolvimento.

Constatou-se, ainda, que os entrevistados percebem que suas atitudes podem, de alguma forma, afetar a sobrevida do rio Ariri. As principais atitudes mencionadas foram: sujar rua, sujar diretamente o rio, poluir o meio ambiente e despejar os dejetos fósseis no rio.

Entretanto, apesar de considerarem o ambiente em que vivem, como regular e reconhecerem a importância do comprometimento individual para a melhoria da qualidade do meio, não há ações efetivas por parte da comunidade nesse sentido.

Sobre sua percepção de quais as mudanças ambientais mais recentes no rio Ariri, verificou-se que a maioria aponta o excesso de lixo como principal causador dessa transformação, o que caracteriza uma boa percepção ambiental no que concerne aos impactos ambientais.

Assim sendo, constataram-se as subcondições a que se encontra a população estudada, com grande déficit de saneamento básico e de educação ambiental. Por conseguinte, identificou-se que há uma interrelação entre as condições básicas de saúde e a qualidade do meio ambiente, o que contribui para uma insipiente qualidade de vida da população pesquisada.

Embora a Lei Orgânica, assim como o Plano Diretor do Município de Ananindeua fomentem a responsabilidade do poder público municipal com as questões ambientais, verificou-se que há uma ausência de políticas 
públicas e ineficácia dos instrumentos normativos vigentes, que ocasiona graves problemas ambientais, não garantindo assim o que determina a Constituição Federal sobre o direito à saúde e ao meio ambiente.

Portanto, observa-se que há a necessidade de um planejamento adequado para as moradias e para a conservação do meio ambiente, tanto no sentido de otimização e de melhoria dos serviços oferecidos à população, no que concerne às questões de saneamento básico, quanto no sentido da preservação ambiental. Logo, são necessárias ações efetivas de educação em saúde e ambiental, as quais devem ser realizadas na comunidade no entorno do rio Ariri, contribuindo para uma efetiva melhoria da qualidade de vida daquela população.

\section{REFERÊNCIAS}

ABELÉM, A. G. Urbanização e remoção: por que e para quem? Belém: NAEA/UFPA, 1988, 188 p.

BERNA, V. Jornalismo ambiental. In: SANTOS, J. E. dos; SATO, M. (Org.). A contribuição da Educação Ambiental à esperança de Pandora. $2^{\mathrm{a}}$ ed. São Carlos: Rima editora, 2003.

CHIZZOTTI, Antonio. Pesquisa em Ciências Humanas e Sociais. $2^{\mathrm{a}}$ ed. São Paulo: Cortez, 1998. (Biblioteca da educação, série 1, Escola, v.16)

COELHO, A. Percepção Ambiental dos Alunos da Faculdade Brasileira, 2002. Disponível: http://www.abe_es.org.br/paginas/trabalhos/.pdf. Acesso: out/2010.

FERNANDES, R. S. et al. Uso da percepção ambiental como instrumento de gestão em aplicações ligadas às áreas educacional, social e ambiental. Vitória, 2008. Disponível: <http//www.redeceas. esalq.usp.br / Percepção_Ambiental.pdf>. Acesso: 18/10/2010.

GONÇALVES, C. W. P. Os (des) caminhos do meio ambiente. $6^{\text {a }}$ ed. São Paulo: Contexto, 1998.

GUTIÉRREZ, F.; PRADO, C. Ecopedagogia e Cidadania Planetária. Guia da Escola Cidadã 3. Instituto Paulo Freire. $2^{\mathrm{a}}$ ed. São Paulo: Cortez, 2000 . 
HILDEBRANDT, P. Teoria Econômica da Indústria da Construção. London: The Macmillan Press, 2004.

LE GOFF, J. História e Memória. 4a ed. Campinas: Editora da Unicamp, 1996.

MARCONI, Marina de Andrade; LAKATOS, Eva Maria. Fundamento da metodologia cientifica. $6^{\mathrm{a}}$ ed., $5^{\mathrm{a}}$ reimpressão. São Paulo: Atlas, 2007. 315p.

MELLO, F. A. O. Análise do processo de formação da paisagem urbana no município de Viçosa, Minas Gerais. 122p. Dissertação de Mestrado em Ciência Florestal. Viçosa: Universidade Federal de Viçosa, 2002.

OKAMOTO, J. Percepção ambiental e comportamento. São Paulo: Mackenzie, 2003.

PIRES, L. M. F. Loteamentos Urbanos: natureza jurídica. São Paulo: Quartier Latin, 2006.

RAMOS, Keite Alice; PEREIRA, Ricardo Augusto Gomes. A Interface de políticas públicas direcionadas para jovens do campo e na cidade: Aproximações possíveis. Encontro Pesquisa em Educação Norte/Nordeste, 2011.12p.

RIBEIRO, M. A. Ecologizar: pensando o ambiente humano. Belo Horizonte: RONA, 2000.

SILVA, E.N.S.; SILVA, C.P.D. Expansão de Manaus como exemplo do processo de extinção dos igarapés. In: FERREIRA, E.J.G. et al. (Org.). Bases científicas para estratégias de prevenção e desenvolvimento da Amazônia. v. 2. Manaus: INPA, 1993.

SILVA, S. R. B. da. Projeto de Orla: bairro da Cidade Velha - do Beco do Carmo ao Arsenal de Marinha. Trabalho Final de Graduação apresentado à Universidade da Amazônia, 2004.

VIEIRA, P. F.; WEBER, J. Gestão dos recursos naturais renováveis e desenvolvimento: novos desafios para a pesquisa ambiental. $3^{\mathrm{a}} \mathrm{ed}$. São Paulo: Cortez, 2002. 